\title{
PENINGKATAN KUALITAS TIDUR LANSIA DENGAN TERAPI PIJAT TENGKUK MENGGUNAKAN VIRGIN COCONUT OIL (VCO)
}

\author{
Nurul Faidah', Ni Wayan Suniyadewi ${ }^{2}$, Chani Mialuara Hutami ${ }^{3}$ \\ 1,2,3 STIKes Wira Medika Bali \\ Corresponding author:nurulfaidah1208@gmail.com
}

\begin{abstract}
Abstrak
Pada lansia terjadi perubahan neurologis secara fisiologis mengalami penurunan jumlah dan ukuran neuron pada sistem saraf pusat yang mengakibatkan lansia tidak dapat memenuhi kebutuhan tidur normalnya. Salah satu terapi meningkatkan kualitas tidur pada lansia adalah melakukan pijat tengkuk menggunakan virgin coconut oil . Tujuan Penelitian: Penelitian ini bertujuan untuk mengetahui pengaruh pijat tengkuk dengan VCO terhadap kualitas tidur pada lansia. Metode:Desain penelitian yang digunakan pra eksperimental dengan One-group Pretest - Posttest Design, teknik sampling yang digunakan dalam penelitian ini adalah non Probability Sampling yaitu dengan purposive sampling. Populasi dalam penelitian ini yaitu, 33 responden dan diperoleh sampel sebanyak 15 responden adapun kriteria inklusi dalam penelitian ini klien dengan gangguan tidur tanpa menggunakan obat penenang atau obat tidur, Klien yang kooperatif dan bersedia menandatangani informed concent, kriteria eksklusi Klien yang memiliki kesadaran composmentis Pelaksanaan penelitian untuk mengukur kualitas tidur diukur dengan Pittsburgh sleep quality index (PSQI) dari. pengukuran kualitas tidur lansia dilakukan sebelum dan sesudah pelaksanaan intervensi. instrumen yang digunakan dalam penelitian ini yaitu Pittsburgh sleep quality index. Intervensi pijat tengkuk dengan Virgin Coconut Oil ini dilakukan 2 kali dalam satu minggu selama 4 minggu. setelah dilakukan uji normalitas data diperoleh hasil 0,28 yang berarti data berdistribusi normal sehingga analisa menggunakan paired T-test. Hasil:Hasil penelitian menunjukan kualitas tidur pre tes rerata kualitas tidur sebesar 7,9 dengan standar deviasi 1,4 dan post tes didapatkan rerata kualitas tidur sebesar 4,5 dengan standar deviasi 0,83. Berdasarkan analisa data menggunakan uji paired T-test diperoleh nilai $p$ value $=0,000<\alpha(0.05)$ yang artinya ada pengaruh pijat tengkuk dengan Virgin Coconut Oil terhadap kualitas tidur pada lansia. Berdasarkan hasil penelitian tersebut, diharapkan lansia dengan masalah kualitas tidur agar rutin melakukan pijat tengkuk dengan VCO secara teratur dan berkesinambungan.
\end{abstract}

Kata Kunci : Pijat Tengkuk, VCO, Kualitas Tidur.

\begin{abstract}
In the elderly, physiological neurological changes have decreased in the number and size of neurons in the central nervous system, resulting in the elderly unable to meet their normal sleep needs. One of the therapies to improve sleep quality in the elderly is doing neck massage using virgin coconut oil. Research Objectives: This study aims to determine the effect of neck massage with VCO on sleep quality in the elderly. Methods: The research design used was preexperimental with One-group pretest-posttest design and the number of respondents was 20 people. The sampling technique used in this study was non-probability sampling, namely
\end{abstract}


purposive sampling. The implementation of the study to measure sleep quality was measured by the Pittsburgh sleep quality index (PSQI) obtained from 33 respondents, 15 respondents who experienced a decrease in sleep quality, the inclusion criteria in this study were clients with sleep disorders without using sedatives or sleeping pills, clients who were cooperative and willing signed the informed concent, exclusion criteria. Clients who have composmentis awareness. The measurement of sleep quality in the elderly was carried out before and after the intervention. The instrument used in this study was the Pittsburgh sleep quality index. Nape massage intervention with Virgin Coconut Oil is carried out 2 times a week for 4 weeks. After the data normality test was carried out, the results were 0.83, which means the data were distributed so that the analysis used the paired t-test. Results: The results showed that the pre-test sleep quality mean sleep quality was 7.9 with a standard deviation of 1.4 and the post test showed a mean sleep quality of 4.5 with a standard deviation of 0.83 . Based on the data analysis using the paired T-test, it was found that the $p$ value $=0.000<\alpha(0.05)$, which means that there is an effect of neck massage with Virgin coconut oil on sleep quality in the elderly. Based on the results of this study, it is hoped that the elderly with sleep quality problems should routinely perform neck massage with VCO regularly and continuously.

Keywords : Neck Massage, Quality of sleeping, VCO.

\section{PENDAHULUAN}

Proses menua merupakan faktor utama terjadinya peningkatan populasi lansia. Proses menua alami ditandai dengan adanya penurunan atau perubahan kondisi fisik, psikologis maupun sosial dalam berinteraksi dengan orang lain. Gangguan dalam pola istirahat-tidur merupakan salah satu masalah yang dialami dalam proses menua.Keluhan sulit masuk tidur atau mempertahankan tidur atau tetaptidak segar meskipun sudah tidur, terbangun lebih awal, mengantuk yang berlebihan merupakan keluhan yang sering muncul pada lansia yang disebabkan oleh kebosanan, kebiasaan, depresi, penyakit organik, perubahan pola tidur seiring dengan bertambahnya usia yang mana tahap ke-3 dan ke-4 dari siklus tidur lansia terjadi dengan frekuensi yang lebih jarang (Potter \& Perry, 2005). Survei yang dilakukan oleh Nasional Institute of Health di Amerika mendapatkan bahwa ditahun 1970 total penduduk yang mengalami gangguan tidur (insomnia) 17 \% dari populasi. Persentase penderita insomnia lebih tinggi dialami oleh kaum lansia. Di mana 1 dari 4 pada usia 60 tahun mengalami sulit tidur yang serius(Yoganita, Sarifah, \& Widyastuti, 2019). Hasil penelitian setiap tahun diperkirakan sekitar 20\%-50\% orang 
dewasa melaporkan adanya gangguan tidur dan sekitar $17 \%$ mengalami gangguan tidur yang serius(N Amir, 2007). Prevalensi gangguan tidur pada lansia cukup tinggi yaitu sekitar 67\%. Penanganan yang selama ini dilakukan di rumah sakit maupun puskesmas untuk mengurangi keluhan gangguan tidur umumnya denganpenatalaksanaan farmakologis dan non-farmakologi yang meliputi pendekatan hubungan antara pasien dan tenaga medis, konseling dan psikoterapi serta sleep hygiene (Japardi, 2002). Terapi non farmakologis untuk meningkatkan tidur lansia salah satunya massage, massage meningkatkan sirkulasi dalam tubuh sehingga merangsang kenyamanan pada tubuh lansia. Massage dalam hal ini yaitu massage pada leher (neck massage) menggunakan Virgin Coconut Oil adapun manfaat memijat bagian leher melancarkan peredaran darah, pijat memepengaruhi kontraksi dinding kapiler sehingga terjadi vasodilatsi pembuluh darah atau melebarnya pembuluh darah kapiler aluran oksigen dalam darah meningkatkan pembuangan sisa-sisa metabolik semakin lancar sehingga memacu hormon endorphin yang berfungsi memberikan rasa nyaman. VCO signifikan memperlihatkan efek antithrombotic dibandingkan dengan minyak kelapa. Level antioksidan yang terkandung di dalam VCO lebih tinggi dibandingkan minyak biji bunga matahari dimana artinya VCO efektif untuk meningkatkan fungsi sel endotel (Widiayanti, 2015). Komponen VCO sendiri berupa asam lemak rantai sedang yang biasa disebut Medium Chain Fatty Acid (MCFA). Asam-asam lemak yang tergolong MCFA mudah diserap sampai ke mitokondria sehingga akan meningkatkan metabolisme tubuh. Keluhan gangguan tidur yang sering dialami lansia membuat peneliti tertarik untuk melakukan penelitian ini. Di wilayah banjar Kayangan sendiri, berdasarkan studi pendahuluan yang dilakukan peneliti dari 10 lansia 6 (60\%) mengalami gangguan tidur, 4 (40 \%) tidak mengalami gangguan tidur. Program yang telah ada untuk lansia adalah hanya senam lansia dua kali seminggu dan posyandu lansia yang rutin dilaksanakan setiap satu bulan sekali.Berdasarkan latar belakang diatas, adanya fenomena menurunnya kualitas tidur pada kaum lansia. tujuan dari penelitian ini untuk mengetahui pengaruh dari neck massage dengan virgin coocnut oil terhadap kualitas tidur lansia. 


\section{METODE}

Metode penelitian yang digunakan oleh peneliti adalah dengan metoda penelitian praeksperimental dengan menggunakan rancangan one group pretest-posttest design. teknik sampling yang digunakan dalam penelitian ini adalah non Probability Sampling dengan purposive sampling. Populasi dalam penelitian ini yaitu, 33 responden dan diperoleh sampel sebanyak 15 responden adapun kriteria inklusi dalam penelitian ini klien dengan gangguan tidur tanpa menggunakan obat penenang atau obat tidur, Klien yang kooperatif dan bersedia menandatangani informed concent, kriteria eksklusi Klien yang memiliki kesadaran composmentis Pelaksanaan penelitian untuk mengukur kualitas tidur diukur dengan Pittsburgh sleep quality index (PSQI) dari. instrumen yang digunakan dalam penelitian ini yaitu Pittsburgh sleep quality index, pengukuran kualitas tidur lansia dilakukan sebelum dan sesudah pelaksanaan intervensi. Intervensi pijat tengkuk dengan Virgin Coconut Oil ini dilakukan 2 kali dalam satu minggu selama 4 minggu, gerakan dalam melakukan pijat tengkuk dengan stroking, kneading, friction masing-masing gerakan 3-5 kali gerakan. Setelah dilakukan uji normalitas data diperoleh hasil 0.28 yang berarti data berdistribusi normal sehingga analisa menggunakan paired T-test.

\section{HASIL}

1. Hasil Karakteristik Dalam Penelitian Ini

a. Karakteristik usia

Tabel 1 Karakteristik Usia Responden

\begin{tabular}{ccrc}
\hline Usia & min & max & rerata \\
\hline & 64 & 72 & 68
\end{tabular}

berdasarkan tabel diatas diperoleh rerata usia responden 68 tahun.

b. Karakteristik Berdasarakan Pendidikan, Jenis Kelamin, Pekerjaan Tabel 2 Karakteristik Responden Berdasrkan Pendidikan, Jenis Kelamin dan Pekerjaan

\begin{tabular}{llc}
\hline No & Jumlah & $\%$ \\
\hline 1.Pendidikan & & \\
\hline Tidak Sekolah & 2 & $13.4 \%$ \\
\hline SD & 5 & $33.3 \%$ \\
\hline SMA & 8 & $53.3 \%$ \\
\hline 2.Jenis Kelamin & & \\
\hline Laki-laki & 4 & $26.7 \%$ \\
\hline Perempuan & 11 & $73.3 \%$ \\
\hline 3.Pekerjaan & & \\
\hline Bekerja & 8 & $53.3 \%$ \\
\hline Tidak Bekerja & 7 & $46,7 \%$ \\
\hline
\end{tabular}

Berdasarkan tabel diatas diperoleh

hasil untuk peniddikan 53,3 \% lulusan SMA, untuk jenis kelamin 73,3\% perempuan, untuk pekerjaan diperoleh hasil 53,3\% tidak bekerja.

2. Hasil Analisis Univariat

a. Kualitas tidur sebelum diberikan pijat tengkuk dengan VCO

Tabel 3 kualitas tidur sebelum diberikan Pijat Tengkuk Dengan Virgin Coconut Oil

\begin{tabular}{ccccc}
\hline $\begin{array}{c}\text { Kualitas } \\
\text { Tidur }\end{array}$ & $\begin{array}{c}\text { Minim } \\
\text { um }\end{array}$ & $\begin{array}{c}\text { Maxi } \\
\text { mum }\end{array}$ & Rerata & $\begin{array}{c}\text { Std. } \\
\text { deviati } \\
\text { on }\end{array}$ \\
\hline Pre & 6 & 11 & 7,9 & 1,4 \\
\hline
\end{tabular}

Berdasarkan tabel diatas kualitas tidur lansia sebelum diberikan perlakuan 
rerata tidur lansia 7,9 dengan standar deviasi 1,4 .

b. Kualitas tidur sebelum diberikan pijat tengkuk dengan VCO

Tabel 2 kualitas tidur setelah diberikan Pijat Tengkuk Dengan Virgin Coconut Oil

\begin{tabular}{ccccc}
\hline $\begin{array}{c}\text { Kualit } \\
\text { as } \\
\text { Tidur }\end{array}$ & $\begin{array}{c}\text { Minim } \\
\text { um }\end{array}$ & $\begin{array}{c}\text { Maxi } \\
\text { mum }\end{array}$ & $\begin{array}{c}\text { Rer } \\
\text { ata }\end{array}$ & $\begin{array}{c}\text { Std. } \\
\text { deviat } \\
\text { ion }\end{array}$ \\
\hline $\begin{array}{c}\text { Postt } \\
\text { est }\end{array}$ & 3 & 6 & 4,5 & 0,83 \\
\hline
\end{tabular}

Berdasarkan tabel diatas kualitas tidur lansia setelah diberikan perlakuan rerata tidur lasnia 4,5 dengan standar deviasi 0,83 .

c. Pengaruh Pijat Tengkuk Dengan VCO Terhadap Kualitas tidur lansia

Tabel 3 Pengaruh Pijat Tengkuk Dengan Virgin Coconut Oil menurukan Kualitas tidur lansia

\begin{tabular}{lcc}
\hline $\begin{array}{c}\text { Kualitas } \\
\text { Tidur }\end{array}$ & $\begin{array}{c}\text { Std. } \\
\text { deviation }\end{array}$ & P value \\
\hline $\begin{array}{l}\text { Pretest- } \\
\text { Posttest }\end{array}$ & 1,12 & 0,000 \\
\hline
\end{tabular}

Berdasarkan tabel diatas setelah diuji normalitas data didapatkan data berdistribusi normal sehingga dianalisis dengan uji paired T-Test dengan hasil $\mathrm{p}$ value 0.000 yang berarti ada pengaruh pijat tengkuk dengan virgin coconut Oil Terhadap peningkatan kualitas tidur lansia.

\section{PEMBAHASAN}

\section{Kualitas Tidur lansia sebelum diberikan Pijat Tengkuk dengan Virgin Coconut Oil}

hasil penelitian diperoleh rerata kualitas tidur lansia 7,9 yang termasuk dalam kategori kualitas tidur buruk. Hasil penelitian ini didukung oleh penelitian yang berjudul Terapi Relaksasi Otot Progresif Terhadap Kualitas Tidur Pada Lansia Di Panti Jompo Yayasan Guna Budi Bakti Medan yang meneliti mengenai Pengaruh, lansia yang menjadi responden setelah diukur menggunakan kuesioner Pittsburgh Sleep Quality Index (PSQI) didapatkan dari 30 responden 20 (66,7\%) lansia mengalami kualitas tidur (Manurung \& Adriani, 2017). Penelitian (Setyoadi, Lestari, \& Kusuma, 2016)yang meneliti tentang Pengaruh Relaksasi Otot Progresif dengan Musik terhadap Kualitas Tidur Lansia di Posyandu Lansia “Anjasmoro” Kelurahan Sukorame Kediri. Hasil penelitian menunjukkan bahwa kualitas tidur responden sebelum diberikan terapi relaksasi otot progresif dengan musik didapatkan rerata 7.50.

Berdasarkan hasil penelitian didapatkan lingkungan Banjar Wangaya Kaja berada di pusat kota Denpasar, memiliki jumlah kepala keluarga sebanyak 260 KK dimana rumah warga berada di pinggir jalan raya yang setiap harinya terjadi kemacetan 
karena berdekatan dengan RS Wangaya dan pasar. Lingkungan Banjar Wangaya Kaja terlihat padat oleh warga dan rumah-rumah warga yang saling berdekatan sehingga udara menjadi cukup panas. Menurut hasil penelitian yang berjudul mengidentifikasi faktor utama penyebab gangguan tidur, yaitu keadaan lingkungan yang berisik(Khasanah \& Hidayati, 2012). Lingkungan dapat menjadi faktor pendukung maupun penghambat tidur. Termasuk faktor lingkungan misalnya pencahayaan, temperatur kamar, ventilasi, dan kebisingan. Lokasi Banjar Wangaya Kaja yang dekat dengan Rumah Sakit Wangaya dan pasar yang setiap hanyinya terjadi kemacetan yang menyebabkan terjadinya kebisingan serta rumah-rumah penduduk yang saling berdekatan sehingga udara menjadi cukup panas. Temperatur yang nyaman, ventilasi yang memadai, dan pencahayaan yang baik, serta lingkungan yang kondusif merupakan faktor yang mendukung untuk tidur. Sebagian besar lansia mengeluh kurang nyaman akibat temperatur dan kebisingan. Bertambahnya usia lansia akan mengalami banyak perubahan pada hidupnya yang akan berdampak pada psikologis pada lansia.
Berdasarkan hasil penelitian sebagian besar lansia mengatakan mempunyai banyak pikiran dan cemas dalam kesehariannya, seperti memikirkan kesehatannya dan sering merasa kesepian karena berpikiran merasa sudah tidak diinginkan lagi oleh keluarganya sehingga lansia mengalami masalah psikologis seperti rasa rindu kepada keluarganya dan hal ini juga yang menyebabkan terlalu banyak pikiran dan timbul rasa cemas yang berlebihan, faktor pensiun juga menimbulkan masalah psikologis pada lansia dimana lansia merasa sebelum pensiun semua orang sangat menghargainya dan memiliki banyak teman namun setelah pesniun lansia merasa diabaikan. Keadaan ini terus berlanjut hingga waktu menjelang tidur, maka lansia tersebut akan mengalami kesulitan untuk memulai tidur dan sering terbangun pada malam hari karena memikirkan tersebut. Sejalan dengan penelitian gangguan psikologis yang terjadi pada lansia antara lain curiga, mudah marah dan egois, kehilangan teman, jauh dari keluarga sehingga menyebabkan lansia merasa kesepian. Faktor tersebut dapat mempengaruhi kualitas tidur pada lansia. Menurut teori (Yuli Aspiani, 2018)perubahan psikologis erat sekali kaitannya dengan perubahan 
fisik, keadaan kesehatan, tingkat pengetahuan, dan pendidikan serta situasi lingkungan. Perubahan dari segi psikologis yang terjadi antara lain sering muncul perasaan pesimis, timbulnya perasaan tidak aman dan cemas akan menimbulkan ganguan pada kualitas tidur lansia. Secara umum, gangguan tidur yang menyebabkan kualitas tidur lansia menurun terjadi karena faktor psikologis. Faktor psikologis seperti kecemasan, stres, ketakutan, dan ketegangan emosional yang dialami lansia. Lansia di kota umumnya mempunyai stresor tambahan seperti keharusan beradaptasi terhadap lingkungan yang semakin padat dan cuaca semakin panas. Tidak jarang kejadian kecil yang dialami lansia menyulut emosi dan menyebabkan kecemasan atau stres yang tentu saja dapat berakibat timbulnya gangguan tidur.

\section{Kualitas Tidur lansia setelah diberikan Pijat Tengkuk dengan Virgin Coconut Oil}

Hasil penelitian diperoleh rerata kualitas tidur lansia 4,5 yang termasuk dalam kategori kualitas baik. Hasil penelitian sejalan dengan penelitian yang dilakukan oleh (Manurung \& Adriani, 2017)yang meneliti tentang pengaruh relaksasi otot progresif dengan musik terhadap kualitas tidur lansia di posyandu lansia "Anjasmoro" Kelurahan Sukorame Kediri. Hasil post test didapatkan hasil rerata sebanyak 4.2, menunjukkan bahwa kualitas tidur responden setelah diberikan relaksasi otot progresif dengan musik mengalami peningkatan. hasil penelitian menunjukan terdapat peningkata kualtas tidur setelah diberikan piat tengkuk menggunakan virgin coconut oil.

Hasil Peneitian ini sejalan dengan penelitian (Permady, 2015)tentang terapi rendam kaki dengan air hangat terhadap kualitas tidur lansia, dari hasil penelitian didapatkan mayoritas responden sebanyak 36 orang $(65,1 \%)$ memiliki kualitas tidur yang baik setelah dilakukan intervensi. Menurut hasil penelitian (AZIS, 2016)Berdasarkan hasil evaluasi ketiga partisipan, terlihat bahwa aromaterapi sereh lebih cepat mengatasi insomnia daripada massage kaki. Namun kombinasi kedua intervensi memberikan efek yang lebih baik. Menurut hasil penelitian Sitralita (2010) mengenai pengaruh latihan relaksasi otot progresif terhadap kualitas tidur pada lansia di Panti Sosial Tresna Werdha Kasih Sayang Ibu Batusangkar, setelah diberikan latihan relaksasi otot progresif, sebagian besar lansia di Panti 
Sosial Tresna Werdha Kasih Sayang Ibu Batusangkar tahun 2010 memiliki kualitas tidur baik, yaitu sebanyak 26 orang.

Permasalahan kualitas tidur jika tidak diatasi dengan baik akan berdampak tehadap masalah yang lain seperti aktifitas, psikososial dan damapak yang lebih parah yaitu terjadi deperesi pada lansia, efek dari pijat tengkuk terhadap penurunan kualitas tidur. efek dari pemijatan karena ada sentuhan pada kutan dan subkutan sehingga akan melonggarakan dan mengurangi peregangan otot. selain itu dari pijatan tubuh akan melepaskan histamine sehingga terjadi vasodilator pembuluh darah dan meningkatkan sirkulasi sehingga melancarkan pembuangan sisa metabolisme dalam tubuh yang dapat merangsang pengeluaran hormon endorphin yang berfungsi untuk meningkatkan kenyamnana. selain efek dari pijatan Virgin Coconut Oil merupakan salah satu bahan yang mengandung Nitric Oxide merupakan salah satu endhothelium-derived relaxing yang memiliki titik tangkap reseptor pada otot polos yang menyebabakan relaksasi dan kontraksi sehingga dapat meningkatakan kenyamanan (Numiati Amir, 2007).
Pijat tengkuk menggunakan virgin coconut oil yang dialkukan selamat 30 menit memberikan efek rileks dan meningkatkan kenyamananan lansia. Pemberian pijat tengkuk dapat meningkatkan kebutuhan tidur secara kuantitas, peningktakan kebutuhan tidur secara kuantitas tersebut dapat disebabkan karena relaksasi efek relakasasi. Latihan relaksasi dapat digunakan untuk memasuki kondisi tidur karena dengan menegangkan dan mengendorkan otot secara sengaja akan membentuk suasana tenang dan santai dimana suasana tenang dan santai diperlukan seseorang untuk memulai tidur (Widiayanti, 2015).

\section{Pengaruh Pijat Tengkuk}

Menggunakan Virgin Coconut Oil Terhadap Kualitas Tidur Lansia.

Berdasarkan hasil penelitian Pengaruh Pijat Tengkuk Menggunakan Virgin Coconut Oil Terhadap Kualitas Tidur Pada Lansia di Banjar Wangaya Kaja Kota Denpasar, hasil menunjukan bahwa rerata nilai kualitas tidur mengalami peningkatan. Berdasarkan hasil di atas dilakukan analisa data menggunakan uji paired T-test diperoleh nilai $p$ value= 
$0,000<\alpha(0.05)$ maka Ho ditolak dan Ha diterima yang artinya ada pengaruh pijat tengkuk mengguankan VCO Tehadap kualitas tidur pada lansia di Banjar Wangaya Kaja Kota Denpasar. Penelitian ini sejalan dengan penelitian yang berjudul Efektifitas Massage kaki dan aromaterapi sereh insomnia dengan hasil (Leo, 2019) berdasarkan hasil evaluasi ketiga partisipan, terlihat bahwa aromaterapi sereh lebih cepat mengatasi insomnia daripada massage kaki. Namun kombinasi kedua intervensi memberikan efek yang lebih baik. sejalan hasil Uji stastistik menggunakan Uji Wilcoxon pada kelompok perlakuan nilai $p$-value $=0,001$ dan kelompok kontrol nilai $p$-value $=0,097$. Hasil uji Mann Whitney nilai post-test $\mathrm{p}$-Value $=0,002$ sehingga Ho ditolak dan Ha diterima (Samiasih, 2013).

Pijat tengkuk (Neck Massage) merupakan teknik pemijatan menggunakan tangan manusia, dengan gerakan tangan yang dapat meningkatkan sirkulasi, melonggarkan dan meregangkan otot. Tekanan terhadap kutan dan subkutan melepaskan histamine sehingga terjadi vasodilator pembuluh darah. Manfaat pijat melancarkan peredaran darah. Pijat mempengaruhi kontraksi dinding kapiler sehingga terjadi vasodilatasi atau 5 kali gerakan, efektifitas pijat tengkuk dilakukan 2 kali dalam satu minggu. Pijat pelebaran pembuluh darah sehingga aliran oksigen dalam darah meningkat, pembuangan sisa-sisa metabolik semakin lancar sehingga memacu hormon endorphin yang berfungsi meberikan rasa nyaman. Pijat menggunakan Virgin Coconut Oil, merupakan salah satu terapi komplementer untuk meningkatan tidur lansia. Manfaat dari pijatan menggunakan virgin coconut oil untuk massage dapat meningkatkan sirkulasi dan merangsang pengeluaran hormon endorphin sedangkan kandungan dari VCO sendiri yaitu Nitric oxide (NO) merupakan salah satu endothelium-derived relaxing yang memiliki titik tangkap reseptor pada otot polos yang menyebabkan relaksasi dan kontraksi. Meningkatnya stimulasi NO meningkatkan smooth muscle contraction pada pembuluh darah dan oksidasi LDL (Low Density Lipoprotein) sehingga dapat melancarkan peredaran darah merangsang pengeluaran hormon endorphin dan meningkatkan kenyamanan pasien sehingga peningkatan tidur lansia (Widiayanti, 2015). Gerakan dalam pijat tengkuk stroking, kneading, friction masingmasing gerakan 3tengkuk yang dilakukan secara kontinu dapat menimbulkan efek relaksasai, efek 
dari pijat tengkuk menggualan virgin coconut oil dapat memberikan efek vasodilatasi pembuluh darah yang dapat meningkatkan sirkulasi sehingga akan merangsang pengeluaran hormon endorphin sehingga meningkatkan kenyamanan pada klien yang dapat meningkatkan kualitas tidur lansia (Hikayati, Flora R, 2012).

Efek dari pemijatan karena ada sentuhan pada kutan dan subkutan sehingga akan melonggarakan dan mengurangi peregangan otot. selain itu dari pijatan tubuh akan melepaskan histamine sehingga terjadi vasodilator pembuluh darah dan meningkatkan sirkulasi sehingga melancarkan pembuangan sisa metabolisme dalam tubuh yang dapat merangsang pengeluaran hirmon endorphin yang berfungsi untuk meningkatkan kenyamnana. Selain efek dari pijatan Virgin Coconut Oil merupakan salah satu bahan yang mengandung Nitric Oxide merupakan salah satu endhothelium-derived relaxing yang memiliki titik tangkap reseptor pada otot polos yang menyebabakan relaksasi dan kontraksi sehingga dapat meningkatakan kenyamanan.

\section{KESIMPULAN}

1. Kualitas tidur Sebelum diberikan intervensi pijat tengkuk dengan Virgin Coconut Oil rerata kualitas tidur lansia 7,9 yang termasuk dalam kategori kualitas tidur buruk.

2. Hasil penelitian diperoleh rerata kualitas tidur lansia setelah diebrikan pijt tengkuk dengan Virgin Coconut Oil 4,5 yang termasuk dalam kategori kualitas baik.

3. Berdasarkan hasil di atas dilakukan analisa data menggunakan uji Paired $T$ - test diperoleh nilai $p$ value $=0,000$ $<\alpha$ (0.05) maka Ho ditolak dan Ha diterima yang artinya ada pengaruh pijat tengkuk menggunakan virgin coconut oil yang berarti ada pengaruh pijat tengkuk dengan Virgin Coconut Oil terhadap kualitas tidur pada lansia di Banjar Wangaya Kaja Kota Denpasar 


\section{REFERENSI}

Amir, N. (2007). Gangguan Tidur pada Lanjut Usia. In Cermin Dunia Kedokteran.

Amir, Numiati. (2007). Gangguan Tidur pada Lanjut Usia Diagnosis dan Penatalaksaan. Cermin Dunia Kedokteran.

AZIS, W. F. AL. (2016). Pengaruh Masase Kaki Dan Aromaterapi Sereh Terhadap Penurunan Insomnia Pada Lansia Di Panti Wredha Daerah Surakarta Publikasi Ilmiah. Naskah Publikasi, 1-12.

Belakang, L. (2019). Studi Kasus Efektivitas Intervensi Massage Kaki , Aromaterapi Sereh \&. 5(2), 42-45.

Hikayati, Flora R, S. P. (2012). Penatalaksanaan Non Farmakologis Terapi Komplementer Sebagai Upaya Untuk Mengatasi dan Mencegah Komplikasi Pada Penderita Hipertensi Primer Di Kelurahan Indralaya Mulya Kabupaten Ogan Ilir. Pengabdian Sriwijaya.

Japardi, I. (2002). Gangguan Tidur.

Khasanah, K., \& Hidayati, W. (2012). Kualitas Tidur Lansia Balai Rehabilitasi Sosial " MANDIRI Semarang. Jurnal Nursing Studies.

Manurung, R., \& Adriani, T. U. (2017). Pengaruh Terapi Relaksasi Otot Progresif Terhadap Kualitas Tidur pada Lansia di Panti Jompo Yayasan Guna Budi Bakti Medan Tahun 2017. Jurnal Ilmiah Keperawatan IMELDA.

Permady, G. G. (2015). Pengaruh merendam kaki dengan air hangat terhadap kualitas tidur lansia di wilayah kerja puskesmas astanalanggar kecamatan losari cirebon jawa barat. In Skripsi Program Studi Ilmu Keperawatan Fakultas Kedokteran dan IImu Kesehatan Universitas Islam Negeri Syarif Hidayatullah Jakarta.

Potter \& Perry. (2005). Buku Ajar Fundamentak Keperawatan. Jakarta: ECG.

Samiasih, A. (2013). PELUANG BEKAM BASAH MENCEGAH PENYAKIT JANTUNG KORONER AKSEPTOR KB DMPA (Indikator Lipid dan Respon Imun). Prosiding Seminar Nasional.

Setyoadi, S., Lestari, R., \& Kusuma, N. (2016). Pengaruh Relaksasi Otot Progresif dengan Musik terhadap Kualitas Tidur Lansia di Posyandu Lansia "Anjasmoro" Kelurahan Sukorame Kediri. Majalah Kesehatan.

https://doi.org/10.21776/ub.majal ahkesehatan.003.01.3

Widiayanti, A. R. (2015). Pemanfaatan Kelapa Menjadi VCO (Virgin Coconut Oil) Sebagai Antibiotik Kesehatan dalam Upaya Mendukung Visi Indonesia Sehat 2015. Prosiding Seminar Nasional Pendidikan Biologi 2015.

Yoganita, N. E., Sarifah, S., \& Widyastuti, Y. (2019). Manfaat Massage Tengkuk Dengan Minyak Zaitun Untuk Mengurangi Nyeri Kepala Pasien Hipertensi. Profesi (Profesional Islam) : Media Publikasi Penelitian, 16(2), 34. https://doi.org/10.26576/profesi.3 21

Yuli Aspiani, R. (2018). BuKu Ajar Asuhan Keperawatan Gerontik. In 1. 